\title{
Three New Articles for Spring 2017: Cooperation and Impact Assessment in Extractive Industries and Implementation of Arctic Council Soft Law
}

Arctic Review on Law and Politics is pleased to present three new articles this spring. All of them concern the High North, in keeping with the journal's aim to provide new scientific knowledge on the area. Two of the articles have a rather similar focus, analyzing the extractive industries in relation to native and indigenous peoples, and the possibilities of reducing risks associated with such extraction. These articles complement each other: one discusses the situation in the United States and the Russian Federation, while the other looks at the conditions in the Northern Scandinavia. Not surprisingly, the two articles have fairly similar conclusions.

By focusing on the situation of indigenous peoples in the United States and the Russian Federation, Alexis Monique Lerner, Victoria Koshurina, Olga Chistanova, and Angela Wheeler, all at the Stanford US-Russia Forum, Stanford University, California, are analyzing the possibilities for Mitigating the Risks of Fracking for Industrial Actors and Northern Indigenous Peoples. Legal precedents for negotiations regarding indigenous rights and natural resources can be found in both the US and the Russian Federation. The authors argue that the explanation for failure in cooperation between indigenous peoples and extractive industries is twofold: first, indigenous land rights lack the consistency which may give indigenous communities control over their resources and cultural preservation; and second, a neutral and objective third-party mediator, whether in the form of a state or an international body, is often silent in, or absent from, the negotiation process, thereby undermining its authority to ensure fair and reasonable deliberations.

Lovisa Solbär and Carina Keskitalo at the Department of Geography and Economic History, Umeå University, have also focused on the third-party role in the extractive industries. By analyzing the role of authority supervision in impact assessment, with case studies from Northern Finland, the authors discuss how to improve impact assessment related to the mining industry. The study shows that third-party review may play 
a role in highlighting the importance of competing land use interests such as reindeer herding. Among the lessons for impact assessment is the need for methodologies for accommodating traditional and practice-based information. Unless these types of sources are considered valid, the possibility of substantializing anticipated impacts and finding solutions along those lines will be missed, with the risk of making things on the ground worse before the need for mitigation measures is comprehended in the face of materializing impacts.

Ida Folkestad Soltvedt at the Fridtjof Nansen Institute, Lysaker, explores a somewhat different topic in her article Soft Law, Solid Implementation? Her point of departure is that the Arctic Council often is criticized for issuing soft law recommendations that are not implemented by its member states. By studying the Norwegian implementation of six Arctic Council recommendations, the author challenges this view. She argues that international soft law is not a uniform phenomenon, and that recommendations may entail certain characteristics - precision, monitoring, and stakeholder involvement - which have significance for the implementation. Having that in mind, the implementation can be enhanced nationally.

Good Arctic reading!!

Øyvind Ravna

Editor-in-chief 